\title{
Valor nutritivo de grãos de sorgo com diferentes texturas do endosperma para frangos de corte
}

[Nutritional value of sorghum grains with different endosperm textures for chicken]

\author{
R.C. Antunes ${ }^{1 *}$, N.M. Rodriguez ${ }^{2}$, L.C. Gonçalves ${ }^{2}$, J.A.S. Rodrigues ${ }^{3}$, \\ N.C. Baião ${ }^{2}$, L.G.R. Pereira ${ }^{4}$, L.J. Lara $^{2}$ \\ ${ }^{1}$ Conselho Nacional de Desenvolvimento Científico e Tecnológico - Brasília, DF \\ ${ }^{2}$ Escola de Veterinária - UFMG - Belo Horizonte, MG \\ ${ }^{3}$ Embrapa Milho e Sorgo - Sete Lagoas, MG \\ ${ }^{4}$ Departamento de Ciências Agrárias e Ambientais - UESC - Ilhéus, BA
}

\begin{abstract}
RESUMO
Utilizaram-se 250 frangos machos, com 22 dias de idade, em ensaio biológico baseado em coleta total de excretas para a determinação da matéria seca metabolizável aparente (MSMA) e dos valores de energia metabolizável (EM) aparente e corrigida de grãos de sorgo com diferentes texturas do endosperma. Os genótipos avaliados foram o BR 007B (textura macia), BR 304 (textura intermediária) e SC 283 (textura dura). As dietas-teste foram compostas por $60 \%$ de dieta-referência (composta a base de milho e farelo de soja) e por $40 \%$ de grãos de sorgo. O experimento foi montado em esquema inteiramente ao acaso, com quatro tratamentos e cinco repetições. Os valores de MSMA foram semelhantes entre os grãos de sorgo ( $\mathrm{P}>0,05)$, sendo $77,09 \%, 81,73 \%$ e $79,69 \%$ para os grãos de textura dura, intermediária e macia, respectivamente. Os valores de energia metabolizável aparente e verdadeira (EMA, EMV) e EMA e EMV corrigidas para a retenção do nitrogênio $\left(E A_{n}\right.$ e $\left.E M V_{n}\right)$ dos grãos de sorgo de textura dura, intermediária e macia foram, respectivamente, 3.022, 3.127, 2.947 e 2.934; 3.335, 3.442, 3.369 e 3.419 ; $3.339,3.450,3.303$ e $3.355 \mathrm{kcal} / \mathrm{kg}$. Os grãos de textura dura (SC 283) apresentaram menores valores de EM $(\mathrm{P}<0,05)$ que os de textura intermediária (BR 304) e macia (BR 007B). As correções dos valores de EM para o balanço de nitrogênio resultou apenas em discretas reduções da EM.
\end{abstract}

Palavras-chave: frango de corte, sorgo, endosperma, digestibilidade, energia metabolizável

\begin{abstract}
Two hundred fifty male chickens, with 22 days old, were used in biological assay based on total excreta collection method. The dry matter apparent metabolizability (DMAM) and metabolizable energy (ME) values of the sorghum grains with different endosperm texture were calculated. The evaluated genotypes were: BR 007B (soft texture), BR 304 (intermediate texture), and SC 283 (hard texture). The test diets were composed by $60 \%$ of reference diet (based on corn and soybean meal) and $40 \%$ of sorghum grain. $A$ completely random experimental design, with four treatments and five replicates was used. The DMAM values were similar among the sorghum grains $(P>0.05)$, being $77.09 \%, 81.73 \%$ and $79.69 \%$ for the hard, intermediate and soft texture grains, respectively. The apparent and true metabolizable energies (AME and TME), and AME and TME corrected for nitrogen retention (AMEn and TMEn) values for the hard, intermediate and soft texture grains were, respectively, 3,022, 3,127, 2,947 and 2,934; 3,335, 3,442,
\end{abstract}

Recebido em 6 de junho de 2005

Aceito em

*Endereço para correspondência (mailing address)

SGAN 914, Ed. Monte Carlo, Bloco B, nº 208 - Asa Norte

70790-140 - Brasília/DF

E-mail: camargos@cnpq.br

Apoio: $\mathrm{CNPq}$ 
3,369 and 3,419; 3,339, 3,450, 3,303 and 3,355kcal/kg. The hard texture grains (SC 283) presented smaller values $(P<0.05)$ of $M E$ in relation to intermediate (BR 304) and soft (BR 007B) texture grains. The corrections of the ME values to nitrogen balance resulted in a discrete reduction of the ME values.

Keywords: Sorghum, endosperm, chicken, digestibility, metabolizable energy

\section{INTRODUÇ̃̃O}

A busca pela redução de custos na produção avícola tem levado à utilização de alimentos energéticos alternativos ao milho. Nas atuais condições brasileiras, o sorgo tem sido considerado como boa alternativa ao milho na alimentação animal em razão do aumento da disponibilidade do grão no mercado nacional nos últimos anos, ao menor custo e graças à composição bromatológica semelhante (Garcia et al., 2005). Segundo a Companhia Brasileira de Abastecimento (Companhia..., 2005), a produção brasileira de sorgo grão, estimada para o ano de 2005 , será de dois milhões de toneladas métricas. Segundo Rostagno et al. (2000) e Valadares Filho et al. (2002), o sorgo possui 10 a $20 \%$ mais proteína bruta que o milho e 10 a $20 \%$ menos extrato etéreo, lisina e metionina. Em média, o milho e o sorgo apresentam valores semelhantes de fibra em detergente neutro, fibra em detergente ácido, fibra bruta, cálcio e fósforo. $\mathrm{O}$ amido é o principal componente do grão de sorgo, que pode representar até $70-75 \%$ do peso seco do grão (Rooney et al., 1980).

O sorgo apresenta grande variabilidade genética para a textura do endosperma, o tecido de reserva do grão. $\mathrm{Na}$ literatura, têm sido descritos grãos de sorgo com endosperma farináceo (textura muito macia) até grãos com endosperma vítreo (textura muito dura) (Maxson et al., 1971; Kirleis e Crosby, 1982), e existem evidências de que a textura do endosperma é relacionada à taxa e extensão das digestibilidades da PB e do amido in vitro (Hoseney et al., 1974) e ruminal in situ em bovinos (Phillipeau et al., 1999).

No entanto, não são conhecidos os efeitos da textura dos grãos de sorgo sobre os valores de energia metabolizável para frangos de corte, a despeito da crescente utilização de sorgo na avicultura. Esta informação será fundamental para a orientação de programas de melhoramento do sorgo granífero para obtenção de genótipos de sorgo com melhor valor nutritivo para frangos e para nutricionistas de aves, com aumento da possibilidade de o sorgo vir a substituir integralmente o milho nas dietas das aves.

O objetivo deste experimento foi avaliar a influência da textura do endosperma dos grãos de sorgo sobre os teores de matéria seca metabolizável aparente e valores de energia metabolizável desses grãos para frangos de corte.

\section{MATERIAL E MÉTODOS}

O ensaio biológico para a determinação dos valores de energia metabolizável aparente e verdadeira, corrigidos ou não para o balanço de nitrogênio, dos grãos de três genótipos de sorgo com diferentes texturas do endosperma, foi realizado em março de 2004. Foi utilizada a metodologia tradicional de coleta total de excretas, de acordo com Albino et al. (1981).

Foram utilizados 250 frangos de corte machos da linhagem Ross 308, com 22 dias de idade, sendo alocados dez frangos por gaiola metálica, com área útil de $1 \mathrm{~m}^{2}$. O tratamento 1 (Trat. 1.) foi composto pela dieta-referência, à base de milho, farelo de soja e complexo vitamínico-mineral, fornecido à vontade (Tab. 1), e os demais tratamentos (2, 3 e 4) foram as dietas-teste, compostas por $60 \%$ da dieta-referência e por $40 \%$ (peso/peso, na base da MN) de grãos de sorgo com diferentes texturas do endosperma moídos a $2 \mathrm{~mm}$. Os grãos de sorgo avaliados foram os dos genótipos BR 007B (Trat. 2), de textura macia (farinácea), o BR 304 (Trat. 3), de textura intermediária, e o SC 283 (Trat. 4), de textura dura (vítrea). A dieta-referência foi balanceada de acordo com os valores nutricionais dos alimentos, citados por Rostagno et al. (2000), para atender às necessidades nutricionais de animais em fase de crescimento. $\mathrm{O}$ ensaio biológico teve 10 dias de duração, sendo os cinco primeiros dias destinados à adaptação às dietas experimentais e os cinco últimos para a coleta de excretas e mensuração do consumo das rações. 
Valor nutritivo de grãos de sorgo...

Tabela 1. Composição da ração-referência fornecida para os frangos de corte

\begin{tabular}{|c|c|c|}
\hline Ingrediente & \multicolumn{2}{|c|}{$\%$ na $\mathrm{MN}$} \\
\hline Milho moído & \multicolumn{2}{|c|}{65,000} \\
\hline Farelo de soja $46 / 80$ & \multicolumn{2}{|c|}{26,500} \\
\hline Óleo de soja & \multicolumn{2}{|c|}{2,000} \\
\hline Farinha de carne e ossos $40 / 6,2$ & \multicolumn{2}{|c|}{5,200} \\
\hline Sal comum & \multicolumn{2}{|c|}{0,360} \\
\hline DL-Metionina, \% & \multicolumn{2}{|c|}{0,210} \\
\hline L-Lisina-HCl, \% & \multicolumn{2}{|c|}{0,125} \\
\hline Suplemento vitamínico/mineral/aminoácido ${ }^{1}$ & \multicolumn{2}{|c|}{0,400} \\
\hline Calcário calcítico & \multicolumn{2}{|c|}{0,205} \\
\hline Total, em \% & \multicolumn{2}{|c|}{100,000} \\
\hline Valores nutricionais calculados ${ }^{2}$ & $\%$ na $\mathrm{MN}$ & $\%$ na MS \\
\hline Matéria seca, \% & 88,04 & 100,00 \\
\hline Proteína bruta, $\%$ & 20,17 & 22,90 \\
\hline Extrato etéreo, \% & 5,17 & 5,87 \\
\hline Cálcio total, \% & 0,77 & 0,87 \\
\hline Fósforo total, \% & 0,62 & 0,70 \\
\hline Fósforo disponível, \% & 0,41 & 0,47 \\
\hline Lisina, $\%$ & 1,16 & 1,32 \\
\hline Metionina, $\%$ & 0,67 & 0,76 \\
\hline $\mathrm{EM}, \mathrm{kcal} / \mathrm{kg}$ & 3.072 & 3.489 \\
\hline
\end{tabular}

${ }^{1}$ Suplemento vitamínico/mineral/aminoácido: Frango Crescimento Completo Vaccinar ${ }^{\circledR}$. Níveis de garantia/kg/produto, segundo o rótulo da embalagem: Vit. A: 2.500.000UI; Vit. D3: 500.000UI; Vit. E: 5.000UI; Vit. K3: 500mg; Vit. B1: 500mg; Vit. B2: $1.000 \mathrm{mg}$; Vit. B6: $1.000 \mathrm{mg}$; Vit. B12: $5.000 \mathrm{mcg}$; Vit. C: $12.500 \mathrm{mg}$; Niacina: $7.500 \mathrm{mg}$; Ácido pantotênico: 2.500mg; Biotina: 15mg; Ácido fólico: 250mg; Colina: $150.000 \mathrm{mg}$; Metionina: $375.000 \mathrm{mg}$; Selênio: $45 \mathrm{mg}$; Iodo: $175 \mathrm{mg}$; Ferro: $12.525 \mathrm{mg}$; Cobre: 2.900mg; Manganês: 19.500mg; Zinco: $13.750 \mathrm{mg}$; Avilamicina: $15.000 \mathrm{mg}$, Monensina: $25.000 \mathrm{mg}$; BHT: 500mg. ${ }^{2}$ Composição calculada de acordo com Rostagno et al. (2000).

Cinqüenta frangos à parte, alojados em cinco gaiolas, receberam a dieta-referência à vontade nos cinco primeiros dias de adaptação e foram submetidos ao jejum de 48 horas para a obtenção das perdas urinárias endógenas e fecais metabólicas de energia, segundo Albino et al. (1981). O jejum foi feito no segundo e terceiro dias do período de coletas.

O consumo das dietas por gaiola foi mensurado diariamente, às $8 \mathrm{~h}$, durante os 10 dias do ensaio. As excretas foram coletadas diariamente, às $9 \mathrm{~h}$ da manhã. As contaminações por ração e penas foram removidas antes das coletas das excretas. Posteriormente, essas foram pesadas e congeladas em freezer a $-10^{\circ} \mathrm{C}$. O piso das gaiolas foi revestido com plástico preto e fino para facilitar as coletas e minimizar as perdas.

Amostras dos grãos de sorgo, das dietas oferecidas e das sobras, obtidas durante $\mathrm{o}$ período de coletas, foram congeladas até as análises. Os grãos de sorgo, as dietas e as sobras foram analisados quanto aos valores de energia bruta (EB); e quanto aos teores de matéria seca total, de proteína bruta, de extrato etéreo, de cinzas e de fibra bruta (Official..., 1980). Os grãos de sorgo foram também analisados quanto aos teores de fenóis totais pelo método do Azul da Prússia, descrito por Price e Butler (1977). A vitreosidade dos grãos foi obtida por meio da determinação visual do escore das áreas de endospermas vítreo e farináceo na secção transversal paralela ao gérmen do grão, segundo Maxson et al. (1971). Para a análise, 30 grãos de sorgo de cada genótipo foram colados em suporte de madeira, posicionados com a face do gérmen voltada para cima. Após a colagem completa, os grãos foram cuidadosamente limados até o centro do grão e escoriados visualmente quanto à vitreosidade. $\mathrm{O}$ escore 1 foi atribuído aos grãos de textura dura (endosperma completamente vítreo), o 2 aos de textura médio dura, o 3 aos de textura média (metade do endosperma vítreo e metade farináceo), o 4 aos de textura médio macia e o 5 aos de textura macia (endosperma completamente farináceo).

Ao final do período de coletas, as excretas (cerca de 500g) foram reunidas em pool, amostradas e secadas. Posteriormente, foram analisadas quanto aos teores de matéria seca total e de energia bruta; e quanto aos teores de proteína bruta (Official..., 1980). 
Os valores de matéria seca metabolizável aparente (MSMA) e os de energia metabolizável aparente (EMA), energia metabolizável aparente corrigida para a retenção de nitrogênio $\left(\mathrm{EMA}_{\mathrm{n}}\right)$, energia metabolizável verdadeira (EMV) e energia metabolizável verdadeira corrigida para a retenção de nitrogênio $\left(E M V_{n}\right)$ da dietareferência e dos grãos de sorgo com diferentes texturas do endosperma foram calculados de acordo com as equações propostas por Matterson et al. (1965).

O delineamento experimental foi inteiramente ao acaso, com quatro tratamentos (uma dietareferência e três dietas-teste) e com cinco repetições por tratamento. Cada repetição foi composta por 10 aves da mesma gaiola. Para a comparação das médias dos valores da energia metabolizável dos grãos de sorgo foi utilizado o teste SNK $(\mathrm{P}<0,05)$, utilizando-se o SAEG (Sistema..., 1999).

\section{RESULTADOS E DISCUSSÃO}

Os valores de composição bromatológica e de energia bruta da dieta-referência (DR) e dos três grãos de sorgo com diferentes texturas do endosperma são vistos na Tab. 2. Os grãos dos três genótipos de sorgo apresentaram composições bromatológicas e valores de energia bruta semelhantes entre si. Os teores de PB dos grãos de sorgo foram maiores do que os citados por Rostagno et al. (2000) e por Valadares Filho et al. (2002), mas o sorgo pode apresentar variabilidade nos teores de PB. Rooney et al. (1980) verificaram que os teores de $\mathrm{PB}$ dos grãos de sorgo variaram de 8,7 a 16,8\%, em 1.160 amostras de grãos analisadas. Cagampang e Kirleis (1984) encontraram variação menor, de 9,8 a 14,0\% de PB, nos grãos de 14 genótipos de sorgo com diferentes texturas do endosperma. Os teores de fenóis totais dos grãos de sorgo foram baixos, sendo classificados como sorgo sem taninos, segundo Price e Butler (1977).

$\mathrm{Na}$ Tab. 3 são apresentados os valores de vitreosidade dos grãos de sorgo, de matéria seca metabolizável aparente (MSMA) e valores de energias metabolizáveis da dieta referência (DR) e dos grãos de sorgo com diferentes texturas do endosperma, na matéria seca. O genótipo SC 283 apresentou escore de vitreosidade de 1,10 , o BR 304 de 2,70 e o BR 007B de 3,70, sendo classificados como grãos de textura do endosperma dura, intermediária e macia, respectivamente, segundo Maxson et al. (1971).

Tabela 2. Composição bromatológica e teores de energia bruta (EB), da dieta-referência e dos grãos de sorgo com diferentes texturas do endosperma, na matéria seca

\begin{tabular}{lccccccccc}
\hline Alimento & $\begin{array}{c}\text { MS } \\
\%\end{array}$ & $\begin{array}{c}\text { EB } \\
\mathrm{kcal} / \mathrm{kg}\end{array}$ & $\begin{array}{c}\mathrm{PB} \\
\%\end{array}$ & $\begin{array}{c}\mathrm{FB} \\
\%\end{array}$ & $\begin{array}{c}\mathrm{EE} \\
\%\end{array}$ & $\begin{array}{c}\text { Cinzas } \\
\%\end{array}$ & $\begin{array}{c}\mathrm{Ca} \\
\%\end{array}$ & $\begin{array}{c}\mathrm{P}_{\text {total }} \\
\%\end{array}$ & $\begin{array}{c}\text { Fenóis } \\
\text { totais } \%\end{array}$ \\
\hline DR $^{1}$ & 88,33 & 4.435 & 20,84 & 4,65 & 6,01 & 5,31 & 1,22 & 0,70 & ND \\
BR 007B & 88,81 & 3.934 & 14,31 & 1,75 & 2,63 & 1,68 & $\mathrm{ND}^{2}$ & $\mathrm{ND}$ & 0,22 \\
BR 304 & 89,31 & 3.840 & 15,00 & 2,34 & 2,79 & 1,82 & $\mathrm{ND}$ & $\mathrm{ND}$ & 0,18 \\
SC 283 & 88,70 & 3.858 & 14,71 & 2,65 & 2,71 & 1,93 & ND & ND & 0,21 \\
\hline
\end{tabular}

${ }^{1}$ DR: dieta referência; ${ }^{2} \mathrm{ND}$ : valores não determinados.

Tabela 3. Valores de matéria seca metabolizável aparente (MSMA) e de energias metabolizáveis aparente (EMA), aparente corrigida para a retenção de nitrogênio $\left(\mathrm{EMA}_{\mathrm{n}}\right)$, verdadeira (EMV) e verdadeira corrigida para a retenção de nitrogênio $\left(\mathrm{EMV}_{\mathrm{n}}\right)$, em $\mathrm{kcal} / \mathrm{kg}$, da dieta-referência (DR) e dos grãos de sorgo com diferentes texturas do endosperma, na matéria seca, para frangos

\begin{tabular}{lcccccc}
\hline Tratamento $^{1}$ & Vítreosidade & $\begin{array}{c}\text { MSMA } \\
\%\end{array}$ & $\begin{array}{c}\text { EMA } \\
\mathrm{kcal} / \mathrm{kg}\end{array}$ & $\begin{array}{c}\mathrm{EMV} \\
\mathrm{kcal} / \mathrm{kg}\end{array}$ & $\begin{array}{c}\mathrm{EMA}_{\mathrm{n}} \\
\mathrm{kcal} / \mathrm{kg}\end{array}$ & $\begin{array}{c}\mathrm{EMV}_{\mathrm{n}} \\
\mathrm{kcal} / \mathrm{kg}\end{array}$ \\
\hline DR & --- & 76,05 & 3.650 & 3.675 & 3.477 & 3.525 \\
SC 283 & 1,10 & $77,09 \mathrm{a}$ & $3.022 \mathrm{Ab}$ & $3.127 \mathrm{Ab}$ & $2.947 \mathrm{Ab}$ & $2.934 \mathrm{Ab}$ \\
BR 304 & 2,70 & $81,73 \mathrm{a}$ & $3.335 \mathrm{Aa}$ & $3.442 \mathrm{Aa}$ & $3.369 \mathrm{Aa}$ & $3.419 \mathrm{Aa}$ \\
BR 007B & 3,70 & $79,69 \mathrm{a}$ & $3.339 \mathrm{ABa}$ & $3.450 \mathrm{Aa}$ & $3.303 \mathrm{Ba}$ & $3.355 \mathrm{Aba}$ \\
EPM & --- & 0,29 & 67,21 & 67,30 & 72,92 & 73,23 \\
CV & --- & $1,44 \%$ & $7,02 \%$ & $6,76 \%$ & $6,99 \%$ & $6,86 \%$ \\
\hline
\end{tabular}

${ }^{1}$ Valores seguidos por letras minúsculas distintas na mesma coluna, comparando os grãos dos genótipos de sorgo, e letras maiúsculas distintas na mesma linha, comparando os valores de EM dos grãos de sorgo, $(\mathrm{P}>0,05)$ pelo teste $\mathrm{SNK}$. EPM=erro padrão da média dos grãos de sorgo; $\mathrm{CV}=$ coeficiente de variação. 
Os valores de matéria seca metabolizável aparente dos grãos de sorgo foram semelhantes $(\mathrm{P}>0,05)$, apesar da diferença na textura do endosperma dos grãos, que variou de $77,09 \%$ para os grãos do genótipo SC 283 a 81,73\% para os do BR 304. Os valores de EMA e EMV dos grãos do genótipo SC 283 (textura dura), do BR 304 (textura intermediária) e de BR 007B (textura macia) foram 3.022 e $3.127 ; 3.335$ e $3.442 ; 3.339$ e $3.450 \mathrm{kcal} / \mathrm{kg}$, respectivamente. Esses valores foram semelhantes $(\mathrm{P}>0,05)$ entre os grãos dos genótipos BR 304 e BR 007B e maiores $(\mathrm{P}<0,05)$ do que os grãos do genótipo SC 283. Os valores de EMV foram, em média, apenas 3,0\% maiores $(\mathrm{P}>0,05)$ do que os valores de EMA dos grãos.

Os valores de EMA dos grãos, obtidos neste estudo, foram semelhantes aos encontrados por Albino et al. (1989) para o sorgo sem tanino $(3.388 \mathrm{kcal} / \mathrm{kg}$, na MS), ao utilizarem galos, e de 6 a $8 \%$ menores do que os citados por Rostagno et al. (2005) para os grãos de sorgo de baixo tanino $(3.511 \mathrm{kcal} / \mathrm{kg}$, na MS).

Nas condições brasileiras, o valor de EMA ainda é a expressão da energia biodisponível dos alimentos mais utilizada no balanceamento de rações para aves em razão do grande volume de dados experimentais disponíveis na literatura (Rostagno et al., 2000) e graças à maior facilidade de obtenção desses valores experimentalmente. No entanto, os valores de EMV, como são obtidos pela correção dos valores de energia bruta correspondentes às perdas urinárias endógenas e fecais metabólicas dos frangos, são aqueles que expressam com maior precisão o valor biodisponível dos alimentos para aves.

Os menores valores de EM, obtidos pelos grãos do genótipo SC 283 (textura dura), atendem à hipótese de que a textura do endosperma influencia a metabolizabilidade da energia dos grãos. O amido do endosperma vítreo (duro) dos grãos está incrustado em forte arcabouço protéico, formado pela matriz protéica espessa e contínua e por corpos protéicos (Sullins e Rooney, 1975). A matriz protéica é constituída por glutelinas, que são proteínas solúveis somente em soluções alcalinas, e os corpos protéicos são constituídos por prolaminas (kafirinas), que são solúveis apenas em substâncias alcoólicas (butanol mais mercaptoetanol) (Chandrashekar e Mazhart, 1999). Segundo Duodu et al. (2003), as duas frações apresentam menores coeficientes de digestibilidade em relação às albuminas e às globulinas, o que explica, em parte, a menor digestibilidade dos componentes nutricionais dos grãos de sorgo em relação aos outros cereais como o trigo, a aveia e a cevada. Para que o amido dos grãos de sorgo esteja disponível é necessário que ocorra antes a digestão dessas frações protéicas (Rooney e Miller, 1982). Os grãos do genótipo SC 283 possuem o endosperma completamente vítreo, para os quais, menores valores de energias metabolizáveis são esperados, em razão da menor disponibilidade do amido à digestão enzimática.

Os resultados obtidos neste estudo reforçam a hipótese de que a textura de grãos de sorgo é critério que deve ser adotado pela empresas melhoradoras de sorgo para a melhoria do valor energético, com vistas à sua utilização nas dietas de aves. Assim, o sorgo poderá substituir o milho sem a necessidade de grandes ajustes no balanceamento das dietas para aves com relação ao valor energético das rações. Espera-se, portanto, que o desempenho das aves possa ser semelhante aos alcançados com dietas a base de milho, porém a custo menor.

Os valores de $\mathrm{EMA}_{\mathrm{n}}$ e $E M \mathrm{~V}_{\mathrm{n}}$ dos grãos de sorgo do genótipo SC 283 (textura dura), do BR 304 (textura intermediária) e de BR 007B (textura macia) foram 2.947 e $2.934 ; 3.369$ e $3.419 ; 3.303$ e $3.355 \mathrm{kcal} / \mathrm{kg}$, respectivamente (Tab. 3). Como ocorreu com os valores de EMA e EMV, os valores de $E_{\mathrm{n}}$ e $E M \mathrm{~V}_{\mathrm{n}}$ foram semelhantes $(\mathrm{P}>0,05)$ entre os grãos dos genótipos BR $304 \mathrm{e}$ BR 007B e maiores $(\mathrm{P}<0,05)$ do que o dos grãos do genótipo SC 283. A correção dos valores de EMA e EMV para a retenção de nitrogênio (para a obtenção dos valores de $E A_{n}$ e $E M V_{n}$ ) produziu apenas discretas modificações nos valores de energia biodisponível dos grãos de sorgo $(\mathrm{P}>0,05)$. As reduções médias obtidas foram de $4,3 \%$ para os grãos de textura dura (SC 283 ), de $0,007 \%$ para os de textura intermediária (BR 304) e de 2,7\% para os de textura macia (BR 007B). Resultados semelhantes foram obtidos por Albino et al. (1982) que também não obtiveram redução nos valores de EM com a correção para a retenção de nitrogênio dos 14 alimentos avaliados. 
Segundo Sibbald e Morse (1982), a correção dos valores de EMV para o balanço de nitrogênio, em condições de balanço positivo de nitrogênio, reduziu, em média, 6 a 7\% o valor de EM dos alimentos. Porém, segundo esses autores, a correção dos valores de EMA e EMV para a retenção de nitrogênio é justificada pela redução da variabilidade dos dados obtidos, pois os valores de energia biodisponível dos alimentos foram obtidos de forma independente do status de nitrogênio em que as aves se encontravam (em ganho ou perda de peso). McNab (2000), no entanto, ponderou que o princípio é justificável uma vez que a função de qualquer sistema de EM é descrever o status energético dos alimentos (ou dietas) e não a habilidade desse em promover a retenção de nitrogênio no animal.

\section{CONCLUSÕES}

Grãos de sorgo do genótipo SC 283 (textura dura) têm menores valores de EMA, EMV, $E A_{n}$ e $E M V_{n}$ que os grãos de sorgo dos genótipos BR 304 (textura intermediária) e BR 007B (textura macia) que são, respectivamente, $3.022,3.127,2.947$ e $2.934 ; 3.335,3.442,3.369$ e $3.419 ; 3.339,3.450,3.303$ e $3.355 \mathrm{kcal} / \mathrm{kg}$. As correções dos valores de EMA para EMV e de ambos para o balanço de nitrogênio não reduzem os valores de EM dos grãos de sorgo, e não têm relação com a textura do endosperma dos grãos de sorgo.

\section{REFERÊNCIAS BIBLIOGRÁFICAS}

ALBINO, L.F.T.; FERREIRA, A.S.; FIALHO, E.T. et al. Determinação dos valores de energia metabolizável e matéria seca aparentemente metabolizável de alguns alimentos. Rev. Soc. Bras. Zootec., v.11, p.207-221, 1982.

ALBINO, L.F.T.; ROSTAGNO, H.S.; FONSECA, J.B. et al. Tabela de composição de alimentos concentrados. V. Valores de composição química e de energia determinados com aves em diferentes idades. Rev. Soc. Bras. Zootec., v.10, p.133-146, 1981.

ALBINO, L.F.T.; RUTZ, F.; BRUM, P.A.R. et al. Energia metabolizável aparente e verdadeira de alguns alimentos determinados com galos. Pesq. Agrop. Bras., v.24, p.1433-1437, 1989.
OFFICIAL methods of analysis. 13.ed. Washington, DC: AO)AC 1980, 1015p.

CAGAMPANG, G.B.; KIRLEIS, A.W. Relationship of sorghum grain hardness to selected physical and chemical measurements of grain quality. Cereal Chem., v.61, p.100-105, 1984.

CHANDRASHEKAR, A.; MAZHAR, H. The biochemical basis and implications of grain strength in sorghum and maize. J. Cereal Sci., v.30, p.193-207, 1999.

COMPANHIA NACIONAL DE ABASTECIMENTO. Avaliação da Safra Agrícola 2004/2005 - Segundo Levantamento. Brasília: Ministério da Agricultura, 2005, 32p. Disponível em: <http://www.conab.gov.br>. Acesso em: 20 de fevereiro de 2005.

DUODU, K.G.; TAYLOR, J.R.N.; BELTON, P.S. et al. Factors affecting sorghum protein digestibility. J. Cereal Sci., v.38, p.117-131, 2003.

GARCIA, R.G.; MENDES, A.A.; COSTA, C. et al. Desempenho da carne de frangos de corte alimentados com diferentes níveis de sorgo em substituição ao milho. Arq. Bras. Med. Vet. Zootec., v.57, p.634-643, 2005.

HOSENEY, R.C.; DAVIS, A.B.; HARBERS, L.H. Pericarp and endosperm structure of sorghum grain shown by scanning electron microscopy. Cereal Chem., v.51, p.553-558, 1974.

KIRLEIS, A.W.; CROSBY, K.D. Sorghum hardness: comparison of methods for its evaluation. In: ROONEY, L.W. MURTY, D.S. (Eds.). INTERNATIONAL SYMPOSIUM ON SORGHUM GRAIN QUALITY, 1982 , Patancheru - India. Proceedings... Patancheru: ICRISAT, 1982. p.231-241.

MATTERSON, L.D.; POTTER, L.M.; STUTZ, N.M. et al. The metabolizable energy of feeds ingredient for chickens. Storrs: The University of Connecticut, Agricultural Experimentation Station, 1965. 11p. (Research Report, 7).

MAXSON, E.D.; FRYAR, W.B., ROONEY, L.W. et al. Milling properties of sorghum grain with different proportions of corneous to floury endosperm. Cereal Chem., v.48, p.478-490, 1971. 
MCNAB, J.M. Rapid metabolizable energy assays. In: D’MELO, J.P.F. Farm animal metabolism and nutrition. Wallingford, UK: CAB International, 2000, p. 307-315.

OFFICIAL methods of analysis. 13.ed. Washington, DC: AOAC 1980, 1015p.

PHILIPPEAU, C.; MONREDON, F.D.; MICHALET-DOREAU, B. Relationship between ruminal starch degradation and the physical characteristics of corn grain. J. Animal Sci., v.77, p.238-243, 1999.

PRICE, M.L.; BUTLER, L.G. Rapid visual estimation and spectrophotometric determination of tannin content of sorghum. J. Agric. Food Chem., v.25, p.1268-1273, 1977.

ROONEY, L.W.; KHAN, M.N.; EARP, C.F. The technology of sorghum products. In: INGLETT, G.E.; MUNCH, L. (Eds.). Cereal for food and beverage. New York: Academic, 1980, p.513-554.

ROONEY, L.W.; MILLER, F.R. Variation in the structure and kernel characteristics of sorghum. In: ROONEY, L.W.; MURTY, D.S. (Eds.). INTERNATIONAL SYMPOSIUM ON SORGHUM GRAIN QUALITY, 1982,
Patancheru - India. Proceedings... Patancheru: ICRISAT, 1982. p.143-162.

ROSTAGNO, H.S.; , L.F.T.; DONZELE, J.L. et al. Tabelas brasileiras para aves e suínos. Viçosa:Imprensa Universitária, 2000. 141p.

ROSTAGNO, H.S.; , L.F.T.; DONZELE, J.L. et al. Tabelas brasileiras para aves e suínos: composição de alimentos e exigências nutricionais. In: ROSTAGNO, H.S. (Ed.), 2.ed., Viçosa:Imprensa Universitária, 2005. 186p.

SIBBALD, I.R; MORSE, P.M. Effects of the nitrogen correction and of feed intake on true metabolizable energy values. Poult. Sci., v.62, p.138-142, 1982.

SISTEMA de análises estatísticas e genéticas SAEG. Viçosa, MG:UFV, 1999. 59p.

SULLINS, R.D.; ROONEY, L.W. Light and scanning electron microscopy studies of waxy and nonwaxy endosperm sorghum varieties. Cereal Chem., v.52, p.361-366, 1975.

VALADARES FILHO, S.C.; ROCHA JR., V.R.; CAPPELLE, E.R. Tabelas brasileiras de composição de alimentos para bovinos. Viçosa: UFV, 2002. 297p. 